\title{
A GESTÃO DE RESÍDUOS DE LABORATÓRIO NA VISÃO DE ALUNOS DE UM CURSO DE GRADUAÇÃO DE QUIMICA E ÁREAS AFINS
}

\author{
Zélia Therezinha Custódio Leite, Sarai de Alcantara e Júlio Carlos Afonso* \\ Departamento de Química Analítica, Instituto de Química, Universidade Federal do Rio de Janeiro, Av. Athos da Silveira Ramos, \\ 149 - Bloco A, 21941-909 Rio de Janeiro - RJ, Brasil
}

Recebido em 21/9/07; aceito em 7/3/08; publicado na web em 26/9/08

\begin{abstract}
WASTE LABORATORY MANAGEMENT UNDER THE VIEWPOINT OF UNDERGRADUATE STUDENTS OF A CHEMISTRY COURSE AND RELATED AREAS. This work presents the students' profile before and after working in the course "Laboratory Chemical Waste Treatment" in the last ten years. The structure of the course is also described. Although students have shown an increasing previous experience on waste management, many fundamental aspects are missing, especially knowledge on the directives focusing environmental aspects. Visits to industrial plants are also essential to better understand the impact of wastes in environment. Most students nowadays consider waste management as an essential part of their professional formation. A good waste management program must consider several topics of extreme relevance.
\end{abstract}

Keywords: waste management; laboratory waste; chemistry teaching.

\section{INTRODUÇÃO}

No $1^{\circ}$ semestre de 1998 , foi instituída uma disciplina eletiva na grade curricular do curso de química, oferecido pelo Instituto de Química da Universidade Federal do Rio de Janeiro (IQ/UFRJ), Tratamento de Resíduos Químicos de Laboratório. Seus pré-requisitos são as disciplinas Análise Quantitativa I e Análise Quantitativa Experimental I, ambas oferecidas no $3^{\circ}$ período do curso em questão. É importante assinalar que não há uma preocupação apenas em formar profissionais capacitados a lidar com resíduos, mas também colaborar na formação cidadã geral, inserindo essa questão em um universo muito mais amplo, envolvendo não só aspectos ambientais, mas também sócioeconômicos, políticos e tecnológicos. Por isso, acredita-se que um aluno ainda no início do curso não tem maturidade suficiente para que possa frequientar a disciplina com o aproveitamento desejado. Com a base oferecida pelas disciplinas nas áreas de Química Orgânica, Analítica e Inorgânica dos três primeiros períodos, os alunos têm condições e são orientados a freqüentá-la a partir do $4^{\circ}$ período.

A proposta desta disciplina segue uma grande ênfase a partir da década de 90, que é a questão da gestão e do tratamento de resíduos químicos gerados em laboratórios. As experiências pioneiras no país ${ }^{1-3}$ e os relatos dos resultados positivos obtidos, particularmente na $\mathrm{UNICAMP}^{3}$ e na UFRGS, ${ }^{1}$ levaram à necessidade de implantar no IQ/ UFRJ uma disciplina que estivesse em sintonia com a tendência então observada, o que também significava uma oportunidade adicional para os alunos investirem em sua formação profissional.

Com carga horária prevista de $5 \mathrm{~h}$ semanais ( $75 \mathrm{~h}$ por semestre), e 10 vagas por turma, a disciplina tornou-se nestes últimos 10 anos uma das eletivas mais procuradas pelos alunos do Instituto, com 152 alunos atendidos em 18 turmas.

\section{ESTRUTURA DA DISCIPLINA}

A organização da disciplina é fundamentada em três tipos de atividades: aulas de laboratório, onde os alunos reconhecem a importância da segregação (separação) na fonte e têm iniciação às téc-

*e-mail: julio@iq.ufrj.br nicas de tratamento das diversas correntes de resíduos identificadas; palestras com especialistas, ocasião em que os alunos têm contato com as tendências mais atuais nas áreas de destinação final, gestão ambiental e legislação aplicada a resíduos no país e no mundo e, visitas técnicas a unidades industriais e centros de pesquisa, mostrando a importância da gestão de resíduos além das fronteiras da Universidade e propiciando aos alunos uma visão fora dos limites acadêmicos. As atividades procuram, na medida do possível, focar outros aspectos relevantes para a formação do químico, favorecendo a inserção da gestão de resíduos como parte integrante da formação desejável de um profissional. Apesar da estrutura ser essencialmente a mesma desde 1998, houve diversas modificações na organização das aulas ao longo do tempo, a fim de incorporar novos recursos didáticos disponibilizados.

Esses recursos didáticos correspondem à exibição de filmes e documentários, a utilização de reportagens publicadas em jornais, revistas, etc., e a navegação na internet (particularmente em portais de órgãos ambientais do Brasil e do mundo). Tais recursos contribuem sobremodo para que os alunos tenham, além da vivência nas aulas, uma visão transdisciplinar que as questões ambientais exigem para que se possa atuar plenamente como profissional e cidadão.

É desejável, na medida do possível, que a sequiência das aulas obedeça a um rodízio visita-palestra-aula prática, de modo que os alunos possam comparar os conhecimentos e vivências adquiridos em cada atividade realizada, auxiliando no objetivo de formação de um espírito crítico e consciente sobre a geração de resíduos nas atividades humanas. Para assegurar tal rodízio, as visitas e palestras são marcadas com até 6 meses de antecedência.

Não há como abordar num período letivo de 15-16 semanas (1 semestre), com a carga horária disponível, todo o universo que engloba a gestão de resíduos. As atividades selecionadas, porém, devem oferecer aos alunos uma visão a mais abrangente possível desse universo, capacitando-os a lidar com outras realidades não previstas na disciplina. Todavia, acredita-se que a abordagem de temas relativos à legislação ambiental e a realização de visitas a empresas que se ocupam do tratamento e destinação final de resíduos são itens obrigatórios na estruturação da disciplina, pois essas atividades dão o fundamento básico a qualquer iniciativa do gênero 
na área educacional.

Procurando mostrar ao aluno a contextualização da gestão de resíduos com aspectos sociais, ambientais, tecnológicos e de cidadania, a forma de avaliação se dá por meio de relatórios (individuais) de cada atividade realizada, e por um trabalho final (em grupo) sobre um tema de interesse da sociedade onde a questão dos resíduos é relevante (por exemplo, lixo urbano, lixo tecnológico, poluição de água doce, aquecimento global, buracos na camada de ozônio, agrotóxicos, coleta seletiva, etc.). Esse tema é escolhido pelos grupos na $1^{a}$ aula, sendo a entrega realizada na última atividade da disciplina. Os relatórios são entregues após 2-3 semanas da realização das atividades, para que os alunos tenham tempo de refletir e amadurecer suas opiniões, explicitando-as na forma de um texto ordenado e embasado por uma bibliografia que lhes é fornecida ou buscada por eles mesmos. O trabalho final tem $50 \%$ de peso na nota final, e a média dos relatórios, o restante.

Desde 2003 é oferecida aos alunos a oportunidade de atuarem como monitores (graduação) ou tutores (pós-graduação) da disciplina, sendo disponibilizadas duas vagas para cada turma. Desde então há pelo menos um monitor (ou tutor) em cada turma. Além das atribuições inerentes à iniciação à docência, o monitor ou tutor desenvolve um pequeno projeto de pesquisa prática (desenvolvimento de rotas de tratamento de resíduos com características especiais) - com exemplos de trabalhos já publicados,$-{ }^{4,5}$ ou então auxilia na introdução de novos recursos didáticos e na revisão dos já utilizados nas aulas.

\section{ORIGEM DOS ALUNOS}

Em média, $85 \%$ das vagas oferecidas a cada semestre letivo foram preenchidas entre 1998 e 2007. Contudo, desde 2004, verifica-se um excedente de alunos inscritos, o que obriga à aplicação de regras de priorização estabelecidas pela diretoria adjunta de graduação do IQ/ UFRJ. Isso reflete certamente um interesse crescente na área ambiental, face aos desafios que a humanidade já enfrenta ou terá de enfrentar ao longo do século XXI. Uma providência tomada face a essa situação foi aumentar o número de vagas por turma de 10 para 12, a partir de 2008, permitindo assim acomodar a atual demanda excedente.

Apesar de dirigida aos alunos do curso de química, existem alunos de outros cursos de graduação que procuraram a disciplina: engenheiros químicos (4\%), químicos industriais (2\%) e licenciandos em química (4\%). As motivações em todos os casos são a ausência de uma disciplina que atenda às expectativas dos alunos na área de gestão de resíduos e, o desejo de ter uma formação além da prevista na grade curricular do curso correspondente.

\section{O ALUNO COMO FOCO CENTRAL DA DISCIPLINA}

Em geral, trabalhos que tratam do gerenciamento de resíduos químicos buscam focar aspectos relativos à implantação de programas de gestão em unidades de ensino ou em disciplinas experimentais. ${ }^{3-12}$ Menos comum é focar o lado humano envolvido neste esforço de gestão, ainda mais que é bem sabido que, sem a participação de toda a comunidade do laboratório, não se pode atingir as metas propostas. ${ }^{1,3,5,7,10}$ Um trabalho publicado há alguns anos ${ }^{13}$ mostra a importância de uma disciplina de tratamento e gestão de resíduos dentro de uma estrutura curricular segmentada da área de química, que dificulta a percepção do caráter interdisciplinar dessa gestão.

Um dos instrumentos mais importantes para que a disciplina mantenha o cumprimento de seus objetivos é a avaliação do perfil dos alunos antes e após cursarem a mesma. Isso é feito através de um questionário específico apresentado a eles no $1^{\circ}$ dia de aula, e outro no penúltimo dia. No primeiro caso, busca-se inferir o grau de informação e esclarecimento dos alunos quanto a questões relativas à geração e gestão dos resíduos em geral. No questionário final, as perguntas têm a intenção de avaliar como a disciplina modificou a visão do aluno para essas mesmas questões.

O questionário inicial é o seguinte: (a) Por que decidiu cursar esta disciplina? (b) Qual é a sua idéia sobre tratamento de resíduos? (c) Você acha que o tratamento de resíduos é vital para uma melhor proteção do meio ambiente? (d) Você conhece alguma lei ou portaria sobre resíduos químicos (ou outros tipos de resíduos industriais) publicada no Brasil ou no exterior? (e) Por que se dá tanta atenção a este assunto nos últimos anos? (f) O que você espera da disciplina?

As perguntas finais são: (a) Os químicos (e profissionais de áreas afins) devem ter noções de tratamento de resíduos para uma melhor qualificação profissional? (b) Qual a atividade da disciplina que foi mais marcante? (c) Você pretende mudar sua postura após freqüentar esta disciplina? (d) O que é necessário para se estabelecer um programa de gestão bem sucedido? (e) Qual é o maior desafio a ser superado para o sucesso desse programa de gestão? (f) Valeu a pena fazer esta disciplina?

Além de um "retrato instantâneo", é também possível delinear um perfil evolutivo dos alunos ao longo dos últimos 10 anos. Os resultados da avaliação dos questionários e a própria vivência dos docentes, monitores e tutores com os alunos são o objetivo deste trabalho.

\section{PERFIL DOS ALUNOS ANTES DA DISCIPLINA}

\section{Por que decidiu cursar esta disciplina?}

Os dados da Tabela 1 mostram que os alunos têm metas cada vez mais bem definidas quando ingressam na disciplina, seja por um desejo pessoal, interesse em atuar profissionalmente no setor, ou exigência do setor de trabalho ou estágio. $\mathrm{O}$ aspecto restritivo a uma curiosidade pessoal tende a desaparecer com o tempo. O item "outros" engloba respostas que também tendem a desaparecer, como: disciplina com horário disponível pelo aluno, disciplina com elevado número de créditos (o aluno do IQ/ UFRJ precisa cursar 24 créditos de disciplinas eletivas para completar as exigências curriculares), ausência de provas escritas e interesse em conhecer atividades industriais. Todas essas respostas não têm conexão com as propostas a que a disciplina se propõe a cumprir.

\section{Qual a sua idéia sobre tratamento de resíduos?}

Na Tabela 2, observa-se que os alunos progressivamente vêm chegando à disciplina com alguma idéia - mesmo que superficial sobre técnicas de tratamento de resíduos de laboratório. Isso decorre

Tabela 1. Razões que levaram os alunos a cursarem a disciplina Tratamento de Resíduos Químicos de Laboratório (valores expressos em percentagem)

\begin{tabular}{|c|c|c|c|c|c|c|c|c|c|c|}
\hline Resposta & 1998 & 1999 & 2000 & 2001 & 2002 & 2003 & 2004 & 2005 & 2006 & 2007 \\
\hline Formação ou capacitação profissional & 40 & 44 & 48 & 46 & 47 & 55 & 55 & 65 & 68 & 76 \\
\hline Curiosidade pessoal & 37 & 33 & 30 & 29 & 32 & 22 & 17 & 13 & 9 & 7 \\
\hline Exigência do local de estágio ou trabalho & 7 & 5 & 7 & 6 & 8 & 8 & 11 & 10 & 15 & 16 \\
\hline Outros & 16 & 18 & 15 & 19 & 13 & 15 & 17 & 12 & 8 & 1 \\
\hline
\end{tabular}


Tabela 2. Idéias sobre tratamento de resíduos dos alunos antes de cursarem a disciplina (valores expressos em percentagem)

\begin{tabular}{|c|c|c|c|c|c|c|c|c|c|c|}
\hline Resposta & 1998 & 1999 & 2000 & 2001 & 2002 & 2003 & 2004 & 2005 & 2006 & 2007 \\
\hline Nenhuma & 75 & 80 & 67 & 63 & 43 & 29 & 29 & 36 & 15 & 10 \\
\hline Precipitação e neutralização & 10 & 7 & 11 & 12 & 12 & 10 & 8 & 7 & 4 & 3 \\
\hline Descarte de sólidos separados dos líquidos & 10 & 7 & 10 & 9 & 12 & 11 & 14 & 10 & 9 & 8 \\
\hline Empresas especializadas fazem este serviço & 5 & 5 & 7 & 8 & 8 & 9 & 9 & 6 & 9 & 8 \\
\hline Segregação e tratamento por corrente & 0 & 1 & 5 & 8 & 25 & 41 & 40 & 41 & 63 & 71 \\
\hline
\end{tabular}

fundamentalmente porque, desde o $1^{\circ}$ período letivo, os alunos das disciplinas experimentais do IQ/UFRJ recolhem os resíduos gerados, separando-os segundo o tratamento e destinação final a ser dado aos mesmos. As regras de segregação são baseadas nos diferentes procedimentos de tratamento a serem empregados em cada caso..$^{1,35}$ Tal postura passou a ser amplamente adotada a partir de 2000, sendo constantemente aperfeiçoada desde então. Mesmo assim, entre 2001 e 2006, pôde-se notar que havia alunos que executavam o recolhimento e a segregação em tais disciplinas sem qualquer preocupação em entender o porquê e a finalidade daqueles procedimentos. Esse ponto reforça a necessidade da persistência de um programa de gestão, não só para que os alunos se conscientizem, mas também para eliminar maus exemplos de postura em laboratório da parte de alunos, funcionários e professores, que tendem a inibir e a desestimular a adoção de práticas mais condizentes com a conduta laboratorial.

\section{Você acha que o tratamento de resíduos é vital para uma} melhor proteção do meio ambiente?

Desde o início, a maioria dos alunos sempre reconheceu a necessidade de tratar resíduos, mostrando com isso uma preocupação com o meio ambiente. Principalmente nos primeiros anos, essa necessidade era vista de maneira apenas superficial e imediatista.

A divulgação de reportagens sobre os problemas ambientais que a humanidade vem enfrentando, ou que terá pela frente num futuro não muito distante, e a ocorrência de diversos desastres ambientais no país (acidentes com refinarias, rompimento da barragem da Companhia Cataguazes de papel e celulose, o Furação Catarina, seca na Amazônia, etc), e no mundo (temporada de furacões de 2005, secas, enchentes, incêndios florestais, etc.) nos últimos anos acentuaram bastante nos alunos a convicção da necessidade da atividade humana harmonizar-se com o meio ambiente. A discussão dos programas de atuação responsável da indústria química (onde a questão dos resíduos é um dos pontos), enfocando aspectos de produção mais limpa $(\mathrm{P}+\mathrm{L})$, a chamada "química verde" e mudanças de tecnologias de processos $^{14-16}$ ajuda bastante nesse trabalho.

\section{Por que se dá tanta atenção a este assunto nos últimos anos?}

Esta pergunta, em conexão com a anterior, mostra uma dominância de razões ambientais e profissionais da parte dos alunos (Tabela
3), em detrimento de motivações de ordem econômica e outras razões menos citadas (obrigação legal, competição de mercado, boa relação com a mídia e boa relação com a comunidade circunvizinha).

Você conhece alguma lei ou portaria sobre resíduos químicos (ou outros tipos de resíduos industriais) publicada no Brasil ou no exterior?

Apesar de se perceber que o aluno chega à disciplina com uma vivência prévia cada vez maior, ainda é clara a deficiência quanto a aspectos de legislação (Tabela 4). Ainda hoje, mais da metade dos alunos não tem qualquer idéia sobre legislação aplicada a resíduos, e mesmo muitos do que têm alguma idéia só a tem superficialmente. Ou seja, esses alunos sabem que existem leis, portarias etc., mas não conhecem seus conteúdos e abrangências. Esse panorama justifica a colocação feita anteriormente de que uma palestra sobre legislação ambiental é um dos alicerces obrigatórios para que a disciplina atinja seus objetivos educacionais, e um dos exercícios mais insistentemente propostos aos alunos é a busca de leis e portarias ambientais no país e no mundo para a realização de seus relatórios.

\section{O que você espera da disciplina?}

Nesta pergunta, há a possibilidade dos alunos terem mais de uma perspectiva pessoal, sendo orientados, nessa hipótese, a escolher a resposta individualmente mais relevante. Embora haja uma preocupação mais imediata em aprender a gerenciar e tratar seus resíduos (Tabela 5), a consciência ambiental na qual a gestão de resíduos é parte integrante vem ganhando força nos últimos anos, valorizando o esforço em oferecer aos alunos uma visão mais abrangente dessa gestão no contexto de uma formação profissional e ao mesmo tempo cidadã.

\section{PERFIL DOS ALUNOS APÓS A DISCIPLINA}

Os químicos (e profissionais de áreas afins) devem ter noções de tratamento de resíduos para uma melhor qualificação profissional?

Desde a primeira edição da disciplina, já era reconhecida a necessidade de saber gerenciar os resíduos gerados em suas atividades. Em

Tabela 3. Razões apontadas pelos alunos para a importância dada à gestão de resíduos (valores expressos em percentagem)

\begin{tabular}{|c|c|c|c|c|c|c|c|c|c|c|}
\hline Resposta & 1998 & 1999 & 2000 & 2001 & 2002 & 2003 & 2004 & 2005 & 2006 & 2007 \\
\hline Proteção ambiental & 43 & 46 & 43 & 45 & 48 & 47 & 43 & 44 & 40 & 48 \\
\hline $\begin{array}{l}\text { Qualificação profissional exigida } \\
\text { pelo mercado }\end{array}$ & 35 & 34 & 37 & 40 & 34 & 42 & 38 & 44 & 41 & 42 \\
\hline Economia de recursos & 10 & 9 & 8 & 9 & 7 & 6 & 6 & 5 & 8 & 5 \\
\hline $\begin{array}{l}\text { Propaganda institucional da } \\
\text { empresa geradora }\end{array}$ & 7 & 5 & 7 & 4 & 8 & 3 & 11 & 4 & 9 & 3 \\
\hline Outros motivos & 5 & 6 & 5 & 2 & 3 & 2 & 2 & 3 & 2 & 2 \\
\hline
\end{tabular}


Tabela 4. Conhecimento dos alunos quanto à legislação ambiental aplicada a resíduos (valores expressos em percentagem)

\begin{tabular}{|c|c|c|c|c|c|c|c|c|c|c|}
\hline Resposta & 1998 & 1999 & 2000 & 2001 & 2002 & 2003 & 2004 & 2005 & 2006 & 2007 \\
\hline Não conheço & 85 & 83 & 77 & 72 & 73 & 67 & 69 & 62 & 59 & 58 \\
\hline Sei que há, mas não sei de seu conteúdo & 7 & 7 & 6 & 8 & 8 & 12 & 10 & 11 & 9 & 12 \\
\hline $\begin{array}{l}\text { Sei que há, e tenho uma vaga idéia de seu } \\
\text { conteúdo }\end{array}$ & 7 & 6 & 9 & 10 & 16 & 14 & 11 & 12 & 13 & 16 \\
\hline Sei que há, e conheço seu conteúdo & 1 & 4 & 8 & 10 & 3 & 7 & 10 & 15 & 19 & 14 \\
\hline
\end{tabular}

Tabela 5. Expectativa dos alunos quanto à disciplina de Tratamento de Resíduos Químicos de Laboratório (valores expressos em percentagem)

\begin{tabular}{lcccccccccc}
\hline Resposta & 1998 & 1999 & 2000 & 2001 & 2002 & 2003 & 2004 & 2005 & 2006 & 2007 \\
\hline Saber como tratar resíduos & 30 & 35 & 32 & 26 & 27 & 25 & 26 & 26 & 28 & 25 \\
Como gerar menos resíduos & 24 & 22 & 19 & 22 & 23 & 24 & 20 & 22 & 20 & 25 \\
Maior capacitação profissional & 20 & 18 & 20 & 22 & 26 & 24 & 23 & 26 & 28 & 24 \\
Conscientização ambiental & 9 & 8 & 11 & 14 & 15 & 17 & 20 & 18 & 18 & 21 \\
Melhor chance de emprego & 15 & 13 & 13 & 11 & 9 & 6 & 7 & 7 & 6 & 5 \\
Outros motivos & 2 & 4 & 5 & 5 & 0 & 4 & 4 & 1 & 0 & 0 \\
\hline
\end{tabular}

relação ao perfil original, nota-se que a maioria dos alunos que não reconheciam, mesmo superficialmente, a importância do tratamento de resíduos na proteção ambiental mudaram de opinião. Por isso, é importante que novas instituições adotem programas de gestão em suas instalações laboratoriais, para que não haja egressos sem as informações mínimas necessárias, mesmo porque é notório que empresas estão exigindo que seus funcionários e estagiários tenham condições e capacitação para gerenciarem os resíduos produzidos nas atividades fabris e laboratoriais (Tabela 1).

\section{Qual foi a atividade mais marcante da disciplina?}

Como era de se esperar, as visitas técnicas sempre foram as atividades mais marcantes para os alunos, principalmente porque tinham um contato com a realidade industrial, que é muito diferente da rotina acadêmica. É nesse contraste que eles percebem como os resíduos laboratoriais são muito diferentes dos industriais (quantidade e qualidade). Isso leva-os constantemente a refletir e a mudar suas opiniões sobre aspectos ambientais relativos a procedimentos e a processos químicos, ampliando enormemente a visão da química aplicada e no cotidiano. A visita a áreas produtivas se constitui numa poderosa ferramenta formadora de uma opinião crítica do aluno.

As aulas de laboratório tiveram uma relativa repercussão nos primeiros anos, em função da coleta de resíduos nas aulas experimentais do IQ/UFRJ ainda se dar de forma isolada e precária. Os resultados obtidos nas aulas práticas da disciplina impactavam fortemente os alunos. Como hoje tal prática é rotina bem estabelecida e amadurecida, muito do impacto dessa atividade na disciplina deixou de existir, sendo o conhecimento da química de elementos que não são estudados nas disciplinas experimentais regulares o fator que as mantêm na estrutura até hoje.

Mesmo assim, os alunos precisam entender que um tratamento completo de um resíduo (aquoso) de laboratório exige a aplicação dos conhecimentos básicos de equilíbrio químico: ${ }^{17}$ neutralização ácido-base; escolha do agente precipitante de metais pesados e/ou de ânions presentes no resíduo, minimizando riscos de solubilização dos mesmos por complexação; aplicação de reações de oxi-redução para oxidar/reduzir espécies presentes no resíduo e/ou destruir o excesso de algum reagente (precipitante, oxidante, redutor) adicionado (sulfeto, $\mathrm{H}_{2} \mathrm{O}_{2}$, zinco etc.). O efluente final deve ser límpido e incolor, ter $\mathrm{pH}$ em torno de 7 e apresentar caráter redox indiferente. ${ }^{1,4,5,18} \mathrm{O}$ material precipitado terá sua destinação final segundo a natureza dos elementos presentes. ${ }^{1,3,18}$ Este quadro mostra o quão importante é a participação do aluno em todas as etapas do tratamento, algumas trabalhosas e demoradas. ${ }^{19,20}$ Muitos deles afirmam que, depois dessa experiência "é melhor não gerar ou minimizar a geração para facilitar a gestão e o tratamento posteriores".

\section{Você pretende mudar sua postura após a realização deste curso?}

Observa-se uma clara evolução da mentalidade dos alunos com o tempo. Se, inicialmente, a mudança era total em vista da pouca ou nenhuma experiência prévia, mesmo empírica, a situação atual mostra que a mudança não atinge a mesma amplitude do passado, principalmente no que diz respeito às aulas práticas, hoje uma rotina no IQ/UFRJ desde o $1^{\circ}$ período. Atualmente, já aparecem alunos com uma boa noção prévia de gestão de resíduos, de modo que para estes, a disciplina consolida conceitos sem que seja necessária uma mudança de conduta. Portanto, ela passa a aprimorar a formação do aluno, ao invés de simplesmente informá-lo, ou auxiliá-lo em sua formação inicial.

\section{O que é necessário para se estabelecer um programa de gestão} bem sucedido?

Em geral, os alunos acreditam que é necessário um conjunto de medidas, mas destacam-se a necessidade de treinar a equipe de laboratório, e saber segregar corretamente as correntes de resíduos para facilitar o tratamento das mesmas (Tabela 6). Como existe a tendência de renovação periódica dos usuários de laboratórios de graduação e mesmo de pesquisa, é consenso entre eles que o treinamento deve ser repetido periodicamente para que não se perca o que já é feito em termos de gestão, bem como aperfeiçoar o próprio programa.

\section{O que é necessário ter no treinamento do pessoal de laboratório?}

Como na pergunta anterior, existe mais de uma medida que deve ser tomada. Na priorização das mesmas, três das opções mostradas na Tabela 7 tiveram igual importância. Ainda assim, destaca-se a necessidade de aliar o trabalho seguro com resíduos com uma base de 
Tabela 6. O que é necessário para um programa de gestão bem sucedido? (valores expressos em percentagem)

\begin{tabular}{lcccccccccc}
\hline Resposta & 1998 & 1999 & 2000 & 2001 & 2002 & 2003 & 2004 & 2005 & 2006 & 2007 \\
\hline Treinamento dos membros do & 38 & 41 & 39 & 39 & 36 & 38 & 38 & 41 & 40 & 42 \\
laboratório & 10 & 10 & 8 & 11 & 13 & 9 & 11 & 12 & 11 & 9 \\
Trabalho em equipe & 13 & 21 & 18 & 19 & 19 & 21 & 20 & 23 & 19 & 24 \\
$\begin{array}{l}\text { Segregar e tratar cada corrente de } \\
\text { resíduos }\end{array}$ & 6 & 7 & 5 & 7 & 6 & 7 & 4 & 6 & 3 & 7 \\
Evitar o passivo & 9 & 8 & 8 & 10 & 8 & 9 & 7 & 6 & 10 & 8 \\
Reduzir o ativo & 24 & 13 & 22 & 14 & 18 & 16 & 20 & 12 & 17 & 10 \\
Outros & & & & & & & & & &
\end{tabular}

Tabela 7. O que essencial num treinamento de pessoal de laboratório? (valores expressos em percentagem)

\begin{tabular}{|c|c|c|c|c|c|c|c|c|c|c|}
\hline Resposta & 1998 & 1999 & 2000 & 2001 & 2002 & 2003 & 2004 & 2005 & 2006 & 2007 \\
\hline Técnicas de tratamento de resíduos & 27 & 30 & 30 & 25 & 26 & 25 & 28 & 24 & 23 & 27 \\
\hline $\begin{array}{l}\text { Ter noções de higiene e saúde } \\
\text { ocupacional }\end{array}$ & 7 & 8 & 8 & 11 & 7 & 11 & 12 & 14 & 12 & 10 \\
\hline $\begin{array}{l}\text { Saber identificar e segregar } \\
\text { correntes de resíduos }\end{array}$ & 24 & 20 & 23 & 23 & 26 & 22 & 21 & 20 & 24 & 27 \\
\hline Conhecer a legislação pertinente & 28 & 24 & 25 & 24 & 26 & 25 & 24 & 27 & 26 & 27 \\
\hline Aulas práticas & 9 & 7 & 7 & 7 & 6 & 9 & 10 & 7 & 7 & 5 \\
\hline $\begin{array}{l}\text { Visitas a empresas de tratamento e } \\
\text { destinação final de resíduos }\end{array}$ & 5 & 11 & 7 & 10 & 9 & 8 & 5 & 8 & 8 & 4 \\
\hline
\end{tabular}

higiene e saúde ocupacionais, pois é considerado que a manipulação de um resíduo pode ser mais perigosa do que a de um reagente. Ou seja, não há trabalho correto em gestão de resíduos sem que haja consciência quanto à própria segurança e da equipe do laboratório. Um aspecto particularmente importante é o conhecimento da parte dos alunos das regras de incompatibilidade química: o que vale para os reagentes aplica-se também aos resíduos gerados após o emprego dos mesmos. ${ }^{21,22}$ A etiquetagem correta e resistente ao tempo é fundamental, não só para evitar enganos no momento da coleta e segregação, mas também não criar um passivo desconhecido e misturar inadvertidamente resíduos incompatíveis., ${ }^{3,723} \mathrm{O}$ investimento de recursos e de tempo necessários para capacitar uma equipe de laboratório é compensado posteriormente pelos resultados que a gestão trouxer em médio e longo prazos. O pessoal do quadro permanente tem função primordial de servir como referência para os novos alunos que ingressam nas disciplinas experimentais.

\section{Qual é o maior desafio a ser superado para o sucesso do programa de gestão?}

Os seis resultados apresentados na Tabela 8 indicam que é preciso, na opinião dos alunos, um conjunto de medidas para que a gestão seja bem sucedida. A tendência em ser menos necessário o trabalho de convenci- mento se deve à própria adesão espontânea das pessoas aos programas de gestão, mesmo de funcionários com longo tempo de serviço. Por isso, vem reduzindo a necessidade de vencer maus hábitos por conta dessa mudança de conduta. Da mesma forma, é fundamental que os resultados alcançados, mesmo que parciais, sejam divulgados à comunidade, pois quando as pessoas vêem esses resultados, o programa tem mais chance de ser aceito de imediato, além de manter a sua credibilidade. Problemas de financiamento do programa de gestão e o apoio da instituição são também entraves que são sempre apontados pelos alunos. Enfim, persistir é fundamental, seja porque o quadro de usuários dos laboratórios muda com o tempo, como também devido a mudanças e avanços nas próprias rotinas da gestão e da legislação ambiental, reformas e mudanças de organização de laboratório, alteração de práticas de ensino e pesquisa, e necessidade de manter o respaldo do programa de gestão.

\section{Valeu a pena fazer esta disciplina?}

A disciplina, na atualidade, atende a todas as expectativas, independente da vivência prévia do aluno. No início, embora houvesse um nível de satisfação elevado, havia algumas críticas quanto à real utilidade de palestras e visitas técnicas, fruto de um amadurecimento ainda incipiente em termos de gestão de resíduos e questões ambientais por parte de alguns alunos.

Tabela 8. Qual é o maior desafio a ser superado neste propósito? (valores expressos em percentagem)

\begin{tabular}{lcccccccccc}
\hline Resposta & 1998 & 1999 & 2000 & 2001 & 2002 & 2003 & 2004 & 2005 & 2006 & 2007 \\
\hline Vencer maus hábitos & 45 & 42 & 45 & 42 & 40 & 35 & 36 & 31 & 27 & 26 \\
Convencer as pessoas a participar & 24 & 26 & 27 & 26 & 22 & 25 & 22 & 23 & 20 & 21 \\
do programa de gestão & 8 & 9 & 8 & 10 & 8 & 15 & 11 & 16 & 13 & 17 \\
$\begin{array}{l}\text { Mostrar resultados } \\
\text { Obter apoio da instituição }\end{array}$ & 9 & 10 & 11 & 11 & 12 & 12 & 15 & 14 & 17 & 17 \\
$\begin{array}{l}\text { Obter verbas para a implantação do } \\
\text { programa de gestão }\end{array}$ & 6 & 7 & 7 & 7 & 9 & 8 & 10 & 10 & 15 & 11 \\
Persistência & 8 & 6 & 2 & 4 & 9 & 5 & 6 & 6 & 8 & 8 \\
\hline
\end{tabular}




\section{CONCLUSÕES}

A mentalidade dos alunos evoluiu notavelmente em uma década, na direção de uma maior conscientização pessoal e profissional na área de gestão e tratamento de resíduos, com uma crescente vivência prévia, mesmo que de forma superficial, ao chegar à disciplina. Contudo, ainda há muito trabalho a ser feito para que o aluno egresso possa ter realmente uma plena visão dos desafios que esta gestão necessita. Os alunos tenderão a exigir mais, do professor e da disciplina, informações que os atualizem. Face ao dinamismo com que as questões ambientais evoluem, o maior desafio para a disciplina e o professor é estar sempre em sintonia com essas evoluções, principalmente em termos de legislação, publicação de novos estudos científicos que comprovem impactos ambientais causados pelo descarte de resíduos sem os cuidados necessários, e evolução do comportamento da indústria química frente ao meio ambiente.

As disciplinas de cursos de graduação na área de resíduos não devem apenas se basear em estudos de caso e de estratégias de segregação, identificação e tratamento. É preciso incorporar outros tópicos da maior relevância, como legislação ambiental, rotas de destinação final, e consciência ambiental. Não há como trabalhar e manejar resíduos sem que se tenha noções de higiene e saúde ocupacional. Há uma clara necessidade de maior contato dos alunos com a realidade industrial e a legislação em vigor no país e no mundo, não só para formação geral, mas também porque contribuem para a formação profissional e cidadã dos mesmos.

É imprescindível uma ampla divulgação dos resultados obtidos na gestão de resíduos na unidade geradora e fora dela, para que a adesão a ela seja mais fácil e o programa seja permanente. Crê-se mesmo que as universidades (e centros de pesquisa) serão forçadas a se enquadrarem pela força da lei ou da evolução da conscientização da sociedade e da comunidade.

A estrutura vigente pode ser adaptada segundo as peculiaridades de cada região (parque industrial disponível, perfil dos palestrantes, atividades econômicas, etc.) onde a instituição de ensino se propõe a ministrar uma disciplina do tipo aqui considerada. Uma vez vencida a inércia da etapa de implantação, e sem esperar pelas movimentações do poder público e a evolução das leis ambientais, o maior ganho a ser obtido será a manutenção desse empreendimento, evitando o risco da acomodação e do esmorecimento do esforço e do empenho iniciais dispendidos.

\section{AGRADECIMENTOS}

Aos 152 alunos que, com seus testemunhos, permitiram a realização desta pesquisa.

Ao Prof. R. R. Menezes (Depto. de Bioquímica) pelo incentivo e participação na implantação da disciplina Tratamento de Resíduos Químicos de Laboratório no IQ/UFRJ.

Aos palestrantes que trocaram experiências e forneceram valiosas informações que colaboraram na formação dos alunos: G. L. Sant'Anna Jr., M. C. Camarota, D. Tabak, G. A. T. Fontoura, L. H. S. Lúcio, A. C. F. Gusmão e E. A. Haddad.

Às empresas que permitiram a realização de visitas técnicas às suas instalações: Grupo S. A. Paulista; Essencis S. A.; Refinaria de Petróleos de Manguinhos S. A.; Refinaria Duque de Caxias (Petrobras/REDUC); Merck S. A.; Bayer S. A.; Tribel S. A. (Tratamento de Resíduos Industriais de Belford Roxo); Centro de Pesquisas Leopoldo Miguez de Mello (CENPES/Petrobras); Instituto de Engenharia Nuclear (IEN/CNEN); Fundação Estadual de Engenharia de Meio Ambiente do Estado do Rio de Janeiro (FEEMA).

Aos monitores (graduação) M. A. B. Moraes, A. A. Silva, O. R. Macedo Neto, B. G. A. L. Borges, A. F. Silva, A. N. Pereira, C. N.
Silva e J. F. Paulino, e aos tutores (pós-graduação) R. M. G. Lima, I. M. Valverde Jr., G. C. Silva, G. N. Bard e R. S. Marinho, que colaboraram no aperfeiçoamento das práticas da disciplina.

Ao setor de transporte da UFRJ que, mesmo muitas vezes em situação precária, disponibilizou os meios necessários para que as visitas técnicas pudessem ser realizadas.

\section{MATERIAL SUPLEMENTAR}

O material suplementar, disponível gratuitamente em http:// quimicanova.sbq.org.br na forma de arquivo PDF, apresenta o programa completo da disciplina Tratamento de Resíduos Químicos de Laboratório, em vigor desde o $1^{\circ}$ período de 2006 (Tabela 1S), e as tabelas contendo as respostas às seguintes perguntas: "Você acha que o tratamento de resíduos é vital para uma melhor proteção do meio ambiente?" (Tabela 2S); “Os químicos (e profissionais de áreas afins) devem ter noções de tratamento de resíduos para uma melhor qualificação profissional?" (Tabela 3S); "Qual a atividade mais marcante da disciplina?" (Tabela 4S); "Você pretende mudar sua postura após freqüentar esta disciplina?" (Tabela 5S); "Valeu a pena fazer esta disciplina?" (Tabela 6S).

\section{REFERÊNCIAS}

1. Cunha, C. J.; Quim. Nova 2001, 24, 424.

2. Amaral, S. T.; Machad, P. F. L.; Peralba, M. C. R.; Camara, M. R.; Santos, T.; Berleze, L.; Falcão, H. L.; Martinelli, M.; Gonçalves, R. S.; Oliveira, E. R.; Brasil, J. L.; Araújo, M. A.; Borges, A. C.; Quim. Nova 2001, 24, 419 .

3. Jardim, W. F.; Quim. Nova 1998, 21, 671.

4. Afonso, J. C.; Silveira, J. A.; Oliveira, A. S.; Lima, R. M. G.; Quim. Nova 2005, 28, 165 .

5. Afonso, J. C.; Araújo, D. F.; Rev. Quim. Ind. 2005, 723, 12.

6. Alberguini, L. B.; Silva, L. S.; Rezende, M. A. O.; Quim. Nova 2003, 26, 291.

7. Afonso, J. C.; Noronha, L. A.; Felipe, R. P.; Freidinger, N.; Quim. Nova 2003, 26, 602.

8. Bendassolli, J. A.; Máximo, F.; Tavares, G. A.; Ignoto, R. F.; Quim. Nova 2003, 26, 612 .

9. Tavares, G. A.; Bendassolli, J. A.; Quim. Nova 2005, 28, 732.

10. Gerbase, A. E; Gregório, J. R.; Calvete, T.; Quim. Nova 2006, 29, 397.

11. Imbroisi, D.; Guaritá- Santos, A. J. M.; Barbosa, S. S.; Shintaku, S. F.; Monteiro, H. J.; Ponce, G. A. E.; Furtado, J. G.; Tinoco, C. J.; Mello, D. C.; Machado, P. F. L.; Quim. Nova 2006, 29, 404.

12. Demaman, A. S.; Funk, S.; Hepp, L. V.; Adário, A. M. S.; Pergher, S. B. C.; Quim. Nova 2004, 27, 674.

13. Abreu, D. G.; Ianamoto, Y.; Quim. Nova 2003, 26, 582.

14. Silva, F. M.; Lacerda, P. S. B.; Jones Jr., J.; Quim. Nova 2005, $28,103$.

15. Prado, A. G. S.; Quim. Nova 2003, 26, 738.

16. Lenardao, E. J.; Freitag, R. A.; Dabdoub, M. J.; Batista, A. C. F.; Silveira, C. C.; Quim. Nova 2003, 26, 123.

17. Adams, D. L.; J. Chem. Educ. 1999, 76, 1088.

18. Armour, M. A.; Browne, L. M.; Weir, G. L.; J. Chem. Educ. 1985, 62, A93.

19. Wiskamp, V.; J. Chem. Educ. 1997, 74, 1152.

20. Nash, J. J.; Meyer, J. A. R.; Nurrenbern, S. C.; J. Chem. Educ. 1996, 73, 1183.

21. Hill, J. W.; J. Chem. Educ. 1981, 58, 996

22. Chang, J. C.; Levine, S. P.; Simmons, M. S.; J. Chem. Educ. 1986, 63, 640.

23. McKusic, B. C.; J. Chem. Educ. 1986, 63, A128. 


\section{A GESTÃo DE RESÍDUOS DE LABORATÓRIO NA VISÃO DE ALUNOS DE UM CURSO DE GRADUAÇÃO DE QUIMICA E ÁREAS AFINS}

\section{Zélia Therezinha Custódio Leite, Sarai de Alcantara e Júlio Carlos Afonso*}

Departamento de Química Analítica, Instituto de Química, Universidade Federal do Rio de Janeiro, Av. Athos da Silveira Ramos, 149 - Bloco A, 21941-909 Rio de Janeiro - RJ, Brasil

Tabela 1S. Programa da disciplina Tratamento de Resíduos Químicos de Laboratório em vigor desde o $1^{\circ}$ período de 2006

\begin{tabular}{lll}
\hline Aula & \multicolumn{1}{c}{ Tema da Aula } & \multicolumn{1}{c}{ Outros objetivos da atividade } \\
\hline \multirow{2}{*}{$\begin{array}{l}\text { Apresentação do curso, objetivos da disciplina e bibliografia; } \\
\text { critérios de avaliação. Organização de grupos para os trabalhos } \\
\text { finais da disciplina. Exibição de filme: "Uma Verdade Inconve- } \\
\text { niente" (2006) }\end{array}$} & $\begin{array}{l}\text { Mostrar aos alunos como a atividade humana pode impactar } \\
\text { em escala global a vida na Terra. Como cada ser humano } \\
\text { deve enfrentar este e outros desafios que a humanidade terá } \\
\text { pela frente ao longo do século XXI. }\end{array}$ \\
\hline & $\begin{array}{l}\text { Palestra: "Atuação responsável na indústria química". A } \\
\text { evolução da questão do tratamento de resíduos nas atividades } \\
\text { industriais: a adoção de tecnologias mais limpas e menos gera- } \\
\text { doras de resíduos; a química verde; o ciclo de vida do produto. }\end{array}$ & $\begin{array}{l}\text { Os alunos têm um primeiro contato com a realidade fora do } \\
\text { laboratório químico. Através de debate entre eles, concluem } \\
\text { que falta ainda muito para que a produção industrial esteja } \\
\text { em harmonia com o meio ambiente. }\end{array}$
\end{tabular}
Comparação entre resíduos laboratoriais e industriais. Exibição de filme "A Química em Nossas Mãos" (2003)

Exibição de filme: "Segurança de Laboratório" (2005). Ensaios de caracterização físico-química de resíduos; práticas de-

3 monstrativas envolvendo a manipulação de materiais contendo metais tóxicos ( $\mathrm{Pb}, \mathrm{Cd}, \mathrm{Hg}, \mathrm{As}, \mathrm{Sb}$ etc.), metais nobres ( $\mathrm{Pt}, \mathrm{Au}$, Ag etc.) e outros 4 composto por estação de tratamento de efluentes, incinerador rotativo e aterro industrial (materiais perigosos - classe I)

Palestra sobre tratamento biológico de efluentes. Exibição de

5 documentários: "A Tragédia da Baía de Minamata" (1976) e "Últimos segundos - O gás da morte de Bhopal" (2001)

6

Aula de laboratório: tratamento de resíduos contendo elementos tóxicos e cancerígenos (Be, $\mathrm{Se}, \mathrm{Tl}$ etc.). Exibição de filme "Resíduos da Construção Civil" (2006) 7 haria Nuclear (IEN/CNEN). Os resíduos radioativos; casos de acidentes reais. Exibição do documentário "Chernobyl” (1987)

Visita a laboratórios da Fundação de Engenharia de Meio

8 Ambiente do Estado do Rio de Janeiro (FEEMA) - apoio ao monitoramento da poluição ambiental

Palestra sobre reciclagem de plásticos. Exibição do documen-

9 tário "Ilha das Flores" (1989) e de reportagens sobre coleta seletiva de lixo (papel, metais, vidro e plástico)
Mostrar o valor da segregação das correntes de resíduos: como seria o tratamento com e sem a segregação? A importância do conhecimento da química em solução aquosa no estabelecimento de estratégias de tratamento de resíduos. A incompatibilidade química.

Os alunos compreendem melhor o porquê da separação na fonte dos resíduos gerados, segundo a destinação final a ser dada aos mesmos. Noções de higiene e segurança industrial. Os alunos descobrem as vantagens e as limitações da aplicação da técnica de tratamento biológico. Também recebem informações sobre tratamentos primário e terciário de efluentes. Antes desta aula, os alunos devem buscar informações sobre a manipulação segura de resíduos contendo esses elementos tóxicos. Aprendem a manusear as fichas de dados de segurança de produtos químicos e outras fontes de informação. Os alunos aprendem a química em solução aquosa de elementos que não são normalmente estudados em disciplinas de laboratório.

Os alunos conhecem um reator nuclear (O Argonauta) e o ciclotron, onde ocorre a produção dos isótopos $\mathrm{I}^{123}$ e $\mathrm{F}^{18}$.

Os alunos têm contato com as técnicas que determinam a balneabilidade de praias, a toxicidade de efluentes (testes de ecotoxicidade) e a invasão de regiões costeiras e rios por organismos exóticos.

O valor da coleta seletiva e da reciclagem. A situação do mercado da reciclagem no Brasil e no mundo. Debate: a reciclagem é devida à conscientização do homem ou tem raízes sócio-econômicas? 
Tabela 1S. continuação

\begin{tabular}{ll}
\hline Aula & \multicolumn{1}{c}{ Tema da Aula } \\
\hline $10 \quad \begin{array}{l}\text { Visita à empresa do segmento químico-farmacêutico. Noções de } \\
\text { medicina ocupacional e proteção laboratorial. Armazenamento e } \\
\text { tratamento de produtos químicos e de seus resíduos }\end{array}$ \\
\hline $11 \quad \begin{array}{l}\text { Visita a aterro sanitário licenciado para resíduos urbanos e classe } \\
\text { O aproveitamento do biogás gerado e o tratamento do chorume } \\
\text { produzido }\end{array}$ \\
\end{tabular}

Palestra sobre legislação ambiental estadual e federal aplicada

12 a resíduos químicos. Exibição do filme "O Dia Depois de Amanhã" (2004)

13

Visita à Refinaria Duque de Caxias - setor de meio-ambiente e de tratamento de resíduos de petróleo

14

Aula de laboratório: tratamento de resíduos contendo metais nobres (Au, Ag, Pt, Pd, Rh etc.)

15 Visita à empresa especializada na preparação de blend para coprocessamento. Legislação pertinente no Brasil e no mundo

Visita ao setor de segurança, meio ambiente e saúde (SMS) do

16

Entrega do trabalho final da disciplina

Outros objetivos da atividade

Os alunos reforçam seus conhecimentos sobre incompatibilidade química e têm noções de PCMSO (Programa de Controle Médico e Saúde Ocupacional) e PPRA (Programa de Prevenção de Riscos Ambientais)

Os alunos aprendem a distinguir entre aterro para materiais classe I e II. A importância da coleta seletiva na redução do volume de lixo urbano. Como é um trabalho de recuperação de áreas degradadas pela disposição inadequada de resíduos e lixo urbano (lixões, terrenos baldios, etc.)

Os alunos aprendem a navegar por portais de agências ambientais do Brasil e do mundo, onde buscam leis e portarias que regulamentam o manejo e a disposição final de resíduos. Após o filme, os alunos debatem sobre o que é ficção e o que é verdade no roteiro apresentado.

Os participantes têm oportunidade de conhecer, mediante uma palestra e uma visita guiada in loco, o que se faz em uma refinaria de petróleo e as suas unidades principais.

Os alunos aprendem a química em solução aquosa de elementos que não são normalmente estudados em disciplinas de laboratório.

Os alunos têm novo contato com práticas de higiene e saúde ocupacionais. Noções sobre a indústria cimenteira.

Os alunos visitam a área de coleta seletiva de resíduos, onde distinguem-se os recicláveis (papel, vidro etc.), e os que serão destinados à incineração, co-processamento, estação de tratamento de efluentes e aterro industrial para materiais classe I.

Tabela 2S. A importância do tratamento de resíduos para a proteção ambiental (valores expressos em percentagem)

\begin{tabular}{lcccccccccc}
\hline Resposta & 1998 & 1999 & 2000 & 2001 & 2002 & 2003 & 2004 & 2005 & 2006 & 2007 \\
\hline É importante & 85 & 88 & 87 & 93 & 93 & 96 & 97 & 99 & 99 & 100 \\
Não é importante & 3 & 3 & 4 & 2 & 3 & 1 & 0 & 0 & 0 & 0 \\
Não sei & 12 & 9 & 9 & 5 & 4 & 3 & 3 & 1 & 1 & 0 \\
\hline
\end{tabular}

Tabela 3S. A importância da gestão de resíduos na formação do profissional de química e áreas afins (valores expressos em percentagem)

\begin{tabular}{lllllllllll}
\hline Resposta & 1998 & 1999 & 2000 & 2001 & 2002 & 2003 & 2004 & 2005 & 2006 & 2007 \\
\hline É importante & 95 & 97 & 98 & 99 & 99 & 100 & 100 & 100 & 100 & 100 \\
Não é importante & 1 & 1 & 1 & 0 & 0 & 0 & 0 & 0 & 0 & 0 \\
Não sei & 4 & 2 & 1 & 1 & 1 & 0 & 0 & 0 & 0 & 0 \\
\hline
\end{tabular}


Tabela 4S. A atividade da disciplina que mais marcou os alunos (valores expressos em percentagem)

\begin{tabular}{lcccccccccc}
\hline Resposta & 1998 & 1999 & 2000 & 2001 & 2002 & 2003 & 2004 & 2005 & 2006 & 2007 \\
\hline Aulas de laboratório & 12 & 12 & 9 & 5 & 6 & 2 & 3 & 2 & 4 & 1 \\
Palestras com especialistas & 13 & 11 & 13 & 7 & 8 & 8 & 10 & 12 & 12 & 13 \\
Visitas técnicas & 75 & 77 & 78 & 88 & 86 & 90 & 87 & 86 & 84 & 86 \\
\hline
\end{tabular}

Tabela 5S. Expectativa de mudança de comportamento dos alunos após freqüentarem a disciplina (valores expressos em percentagem)

\begin{tabular}{lcccccccccc}
\hline Resposta & 1998 & 1999 & 2000 & 2001 & 2002 & 2003 & 2004 & 2005 & 2006 & 2007 \\
\hline Nenhuma & 3 & 2 & 2 & 1 & 1 & 0 & 0 & 0 & 1 & 0 \\
Mudança parcial & 36 & 40 & 40 & 43 & 44 & 45 & 51 & 53 & 60 & 61 \\
Mudança total & 61 & 58 & 58 & 55 & 53 & 55 & 44 & 38 & 34 & 34 \\
Não preciso mudar de conduta & 0 & 0 & 0 & 1 & 2 & 0 & 5 & 9 & 5 & 5 \\
\hline
\end{tabular}

Tabela 6S. Valeu a pena fazer a disciplina? (valores expressos em percentagem)

\begin{tabular}{lcccccccccc}
\hline Resposta & 1998 & 1999 & 2000 & 2001 & 2002 & 2003 & 2004 & 2005 & 2006 & 2007 \\
\hline Sim, plenamente & 55 & 67 & 69 & 74 & 75 & 83 & 82 & 94 & 96 & 99 \\
Sim, parcialmente & 40 & 31 & 28 & 25 & 24 & 17 & 18 & 6 & 4 & 1 \\
Não & 5 & 2 & 3 & 1 & 1 & 0 & 0 & 0 & 0 & 0 \\
\hline
\end{tabular}

